\title{
Ansar al-Islam og kurdisk islamisme
}

Ansar al-Islam og mulla Krekar har figurert i utallige norske avisartikler i tiden som har gått siden han ble arrestert i Jordan. Likevel er det få som vet noe substansielt om Krekar og grupperingen han stiftet i Nord-Irak.

Av Jan Bojer Vindheim, som for tiden arbeider med en mastergrad i religion ved NTNU. Har utgitt blant annet «estens mysterier» og «kn i hampen».

DENNE ARTIKKELEN TAR for seg samspillet mellom religion og politikk i de kurdiske områdene av Irak. Spesielt tar den for seg hvordan den islamistiske grupperinga Ansar al-Islam i siste halvdel av I990-åra fant seg et fysisk, ideologisk og åndelig rom i det kurdiske selvstyreområdet.

\section{Kurderne i Irak}

De nåværende landegrensene i Midtøsten ble trukket opp etter første verdenskrig gjennom en avtale mellom de seirende maktene, først og fremst England og Frankrike. Områder erobret fra det osmanske imperiet ble fordelt på flere stater. Løfter til de kurdiske folkegruppene om en egen stat ble ikke respektert, i stedet ble områdene med kurdisk flertall delt mellom de nye statene Syria, Irak og Tyrkia. Også Iran, hvis grenser ikke ble endret, hadde og har et betydelig kurdisk mindretall. Den største kurdiske befolkningen finnes i Tyrkia, mens den største andelen kurdere i forhold til befolkningen som helhet er i Irak, der kurderne utgjør ca $20 \%$ av folketallet. ${ }^{\text {}}$

Både i Tyrkia, Irak og Iran har kurdiske nasjonalister drevet geriljakrig mot de sen- trale myndighetene mer eller mindre kontinuerlig siden slutten av første verdenskrig. De kurdiske geriljasoldatene, peshmerga, er kjent som seige og nådeløse krigere både overfor utenforstående og overfor rivaliserende peshmergaer. ${ }^{2}$

I de kurdiske områdene av Irak bor det anslagsvis fire millioner mennesker. Flertallet av disse er sunnimuslimer, men det er også en sjiittisk minoritet blant irakiske kurdere. De lokale variantene av sunniislam er sterkt preget av to store sufiordener: Det er naqshbandi-sufiene i de nordvestlige områdene mot Syria og Tyrkia, og qadiri-sufiene i de østlige grenseområdene mot Iran. Sufistenes tolerante praksis har bidratt til å opprettholde en betydelig grad av religiøst mangfold i området. ${ }^{3}$

I tillegg til islam, ofte også som innslag i muslimsk praksis, finnes det i de kurdiske fjellområdene sterke understrømninger av eldre religioner. Disse tradisjonene, som til en viss grad er avledet av den gamle zoroastriske religionen, har nedfelt seg i egne religiøse grupperinger som yezidi og haqqah. Det finnes også kristne grupper som tilhører den assyriske kirke eller andre orientalske kirkesamfunn. 
Dessuten er det et lite antall kurdisktalende jøder, hvorav de fleste har slektninger i Israel. ${ }^{4}$

Grunnet det ekstremt oppdelte fjellandskapet har de ulike landsbyene kunnet bevare hvert sitt religiøse og kulturelle særpreg. Den geografiske oppsplittingen har bidratt til kurdernes sterke klansbånd og til blodige konflikter mellom ulike klaner og grupper av klaner. Hver landsby domineres ofte av én religiøs retning, slik at flertallet av innbyggerne kan være sunni eller sjia, yezidi eller haqqah, eller kanskje tilhengere av en spesiell sufi-sjeik. ${ }^{5}$

\section{Kurdisk nasjonalisme i Irak}

Den kurdiske nasjonalismen som vokste fram fra sist på attenhundretallet, hadde $\mathrm{i}$ hovedsak et klart verdslig preg, og de skiftende irakiske regjeringers bruk av religiøs propaganda i kampen mot kurdisk nasjonalisme har styrket denne tendensen i irakisk Kurdistan. En annen faktor som har bidratt til dette sekulære preget er de marxistiske tendensene blant kurdiske intellektuelle. Til sammen har disse to elementene skapt en sterk motstand mot islamisme i de kurdiske områdene av Nord-Irak. De ulike regjeringene i Bagdad har derfor kunnet hisse til kamp mot «gudløse kurdere» når det har passet slik. ${ }^{6}$

I forhold til situasjonen i nabolandene har kurderne i Irak hatt stor frihet til å dyrke og utvikle sin egen kultur. I ı9ı8 ble det innført undervisning på kurdisk, og et kurdisk skriftspråk skrevet med det arabiske alfabetet ble utviklet. Etter annen verdenskrig har kurdisk vært brukt som undervisningsspråk, og en rekke kurdiske medier fra aviser og tidsskrifter til radio og etter hvert tv var i lange perioder $i$ virksomhet med like stor frihet som de arabiskspråk- lige. ${ }^{7}$

Under Baathpartiets diktatur etter I968 varierte situasjonen fra perioder av relativ ro til krig og undertrykkelse. Deler av Kurdistan var til enhver tid kontrollert av ulike peshmerga-grupper, ofte med støtte fra Iran og eller Syria. Også soldater fra den tyrkiske radikale kurderorganisasjonen PKK har ofte søkt tilflukt i de irakiske fjellene. ${ }^{8}$

Baathregimet tok - i likhet med tidligere irakiske regimer - etter hvert $\mathrm{i}$ bruk en religiøs retorikk som forsterket den sterke sekulære tendensen blant irakiske kurdere. En muslimsk renessanse i byene etter annen verdenskrig ga seg nok utslag i økt oppslutning om Det muslimske brorskap, men fikk lite gjennomslag på landsbygda og rokket i liten grad ved den kurdiske nasjonalismens grunnleggende sekulære karakter. ${ }^{9}$ Kurdiske muslimer har dessuten blitt frastøtt av muslimbrødrenes panarabiske ideologi, som ga seg utslag $i$ uttalt motstand mot kurdisk nasjonsbygging. ${ }^{\text {I }}$

Baathpartiet forsøkte å oppmuntre radikale sunnigrupper som motvekt mot den iranske støtten til både sjiitter og de sekulære nasjonalistpartiene i Kurdistan, men opplevde til sin forskrekkelse at disse kurdiske sunnigruppene vendte sine våpen også mot regimet i Bagdad som ble karakterisert som "en fiende av gud". Allerede $\mathrm{i}$ I986 sendte det lokale Baathpartiet meldinger om regimefiendtlig islamistisk aktivitet i Halabjaområdet. Sammen med den iranske militære framgangen kan derfor frykt for islamistisk agitasjon ha vært medvirkende årsaker til det brutale angrepet på Halabja i iو88. ${ }^{\text {II }}$

Krigen mellom Irak og Iran fra I980I988 førte til enorme ødeleggelser i de kur- 
diske områdene. Kurdiske geriljagrupper med støtte fra Iran tok makta i store deler av Nord-Irak, regjeringa i Bagdad svarte med en nådeløs kampanje for å utslette den kurdiske kulturen. Tusenvis av landsbyer ble systematisk ødelagt og titusener døde lagt i massegraver. De overlevende ble samlet i byene. Kampdyktige menn flyktet opp i fjellene, og mange flyktet naturligvis også ut av Irak. Kampanjen ble kalt kalt alAnfal, etter Koranens Sura 8, som omhandler en berømt seier over de vantro og hvordan krigsbyttet ble fordelt blant de seierrike troende. ${ }^{\mathrm{I} 2}$

Da iranske styrker støttet av peshmergas erobret et område rundt byen Halabja vinteren I988 svarte det irakiske regimet ved å la flyvåpenet slippe gassgranater over området. Anslagsvis 5000 mennesker menn, kvinner og barn - ble drept. Dette er blitt en merkedag i den kurdiske kalenderen, et grusomt eksempel på undertrykkelsen av det kurdiske folk, hvis minne forener alle kurdere på tvers av hva som ellers måtte skille dem fra hverandre av nasjonale, religiøse eller politiske konflikter. ${ }^{13}$

\section{Det autonome kurdiske området}

Golfkrigen i I99I fikk regimet i Bagdad til å vakle, men gikk ikke så langt som å velte Saddam Hussein. Derimot ble befolkningen i Irak oppfordret til å reise seg mot ham, blant annet gjennom sendinger på amerikanskfinansierte radiostasjoner. Den kurdiske befolkningen og tusenvis av peshmergas jaget den irakiske hæren ut av de nordlige provinsen og ventet seg internasjonal støtte. Da denne støtten uteble rykket regjeringshæren snart inn igjen i de kurdiske områdene. ${ }^{\mathrm{I}}$

Befolkningen ventet seg det aller verste, med Anfal-kampanjen og massakren i Halabja i friskt minne. Hundretusener av mennesker flyktet opp i fjellene og forsøkte å ta seg inn i Tyrkia og Iran. Tyrkia stengte sin grense for flyktningene, og fjernsynsseere over hele verden fikk se store mengder hjelpeløse mennesker som sultet og frøs i ingenmannsland. For å lette presset på nabolandene opprettet USA og Storbritannia, med støtte i en FN-resolusjon, en beskyttet sone langs grensen, der irakiske fly ble nektet overflyging. Sonen ble gradvis utvidet, og høsten 1992 trakk Baathregimet alle sine funksjonærer ut. Innen det området som oppsto på denne måten ble det opprettet en autonom sivil forvaltning, uavhengig av Bagdad, og i I993 ble det avholdt valg til et kurdisk parlament, med sete i den historiske byen Irbil. ${ }^{15}$

I det autonome området ble byer og landsbyer som var blitt ødelagt under Anfal-kampanjen og oppstanden i I99I sakte gjenreist, men den sosiale strukturen var ødelagt $i$ en slik grad at det langt på vei er et helt nytt kurdisk samfunn som er blitt bygd opp i Nord-Irak etter I99I. Området er i praksis delt mellom de to partiene KDP (Kurdistans demokratiske parti) og PUK (Kurdistans patriotiske union). Sælig KDP er i stor grad bygd opp på den tradisjonelle kurdiske klanadministrasjonen. Høvdingen, agaen, i den enkelte landsby forhandler på vegne av alle innbyggerne og fordeler de tilgjengelige godene til dem. Han er både dommer og militsleder. Et slikt system gir naturligvis et betydelig rom for korrupsjon og nepotisme. ${ }^{16}$

Grensene mellom de to partiene følger i hovedsak en kulturell bruddlinje mellom grupper i nordvest som taler den kurdiske dialekten kormanji og gruppene i sørøst 
som taler sorani. I muslimsk forstand er dette også grensa mellom de to store sufiordnenes innflytelsessfære. KDP dominerer i de områdene der naqshbandiordenen tradisjonelt har innflytelse, og PUK der qadari-sufiene er aktive. ${ }^{\text {I7 }}$

\section{Framveksten av islamistiske grupper}

Samtidig som KDP og PUK, med sin topptunge styring fra tradisjonelle klanledere, rivaliserte om makta i det frie Sør-Kurdistan, oppsto det et tredje parti med en appell som overskred de tradisjonelle klangrensene og som lovte å avskaffe korrupsjon og vanstyre. Det var den islamistiske bevegelsen IMK (Islamic Movement of Kurdistan) ledet av Uthman Ali Aziz, en mann av geistlig bakgrunn fra Halabjaområdet. IMK fikk ved valgene i I993 6\% av stemmene $\mathrm{i}$ det kurdiske autonome området som helhet. Siden det var en sperregrense på $7 \%$ ble partiet ikke representert i det kurdiske parlamentet i Irbil.. ${ }^{18}$

IMK ble opprettet i I987, midt under Saddam Husseins Anfal-kampanjer. Den springer altså ut av et samfunn i voldsom forvandling, der det tradisjonelle landsbyfellesskapet blir revet opp med militær makt, og helt nye sosiale situasjoner oppstår. Store deler av den kurdiske befolkningen er på flukt, og har søkt inn til byene. Den islamske bevegelsen har nok funnet næring i forestillinger om det islamske fellesskapet $\mathrm{i}$ landsbyene, men den oppstår og utvikler seg først og fremst i den rotløse nyurbaniserte bybefolkningen og da sælig blant ungdommen. ${ }^{\text {.9 }}$

Det kurdiske selvstyreområdet var fram til krigen i 2003 utsatt for en dobbelt blokade; hele Irak var utsatt for internasjonale sanksjoner, og de kurdiske områdene var dessuten utsatt for sanksjoner fra regimet i Bagdad. Parlamentet i Irbil, og de regjerende politikerne fra PUK og KDP, hadde derfor små økonomiske muligheter for å bygge opp infrastrukturen etter krigen eller sikre innbyggerne de nødvendige offentlige tjenester. De islamske bevegelsene, hvorav IMK var den viktigste, kunne derimot dra nytte av økonomisk støtte fra Saudi-Arabia, kanalisert giennom slike institusjoner som International Islamic Relief Organization. ${ }^{20}$

I IMKs kjerneområde ble det bygd en

De islamske gruppene skaffet seg støtte ved å gjennomføre ulike former for sosiale hjelpetiltak.

rekke flotte moskeer, og både der og i øvrige deler av irakisk Kurdistan skaffet de islamske gruppene seg støtte ved å gjennomføre ulike former for sosiale hjelpetiltak knyttet til islamsk agitasjon. Enker som fikk mat eller annen hjelp måtte bære hijab, studenter som fikk økonomisk hjelp måtte omvende hele familien til den rette praksis. $^{21}$

Innflytelsen til IMK minket imidlertid raskt etter 1996, som følge av den internasjonale politiske utviklingen. USA og Frankrike forhandlet i 1996 fram en avtale som ga de kurdiske selvstyre-myndighetene tilgang til midler fra salg av irakisk olje gjennom det såkalte olje for mat-programmet. Behovet for sosiale tiltak fra de islamistiske misjonsorganisasjonene ble dermed sterkt redusert. IMK endret nå taktikk, og startet en væpnet kamp mot PUK og KDP som med sin avslappede holdning til islamsk levesett ble ansett som 
frafalne. Som base opprettet islamistene en enklave mellom PUKs område og den iranske grensa med senter i Halabja. Her ble det innført et shariabasert styre etter mønster av Talibanregimet i Afghanistan. ${ }^{22}$

\section{Ansar al-Islam og mulla Krekar}

Nå la det iranske regimet også press på sine klienter, som på ulike vis omfattet

\section{Ansar hadde pålagt småjenter å} dekke seg til, forbudt sang og dans $i$ brylluper og ilagt bøter for latter.

både PUK og IMK. Derfor ble det i I997 inngått en våpenhvileavtale som innebar at IMK fikk det sivile herredømme rundt Halabja, mens PUK skulle ha det militære ansvaret. ${ }^{23}$

Blant de radikale islamistene som støttet IMK var det ikke alle som ville akseptere en slik pragmatisk avtale med fienden. Flere ytterliggående fraksjoner brøt ut av IMK, nektet å akseptere våpenhvileavtalen og befestet landsbyer i utkanten av IMKs område langs grensen til Iran. Disse gruppene kan plasseres innenfor den islamske fornyelsesretningen salafiya, men har også elementer av den konservative retningen wahhabi-islam. Wahhabi-retningen er rådende i Saudi-arabia, og hadde gjennom sine økonomiske bidrag betydelig innflytelse på IMK. De mer ekstreme versjonene av salafiya-islam mener saudiaraberne har solgt sin sjel til USA, og bare bruker sin islamisme som et hyklersk alibi. ${ }^{24}$ På samme måte mente utbryterne fra IMK at denne organisasjonen sviktet i gjennomføringen av sharia i tillegg til å ha forrådt sine prinsipper ved å gå inn i et formalisert samarbeide med PUK og KDP. ${ }^{25}$

Den viktigste av disse salafi-gruppene er Ansar al-Islam, hvis grunnlegger og tidligere leder Najmuddin Feraj Ahmed er bosatt i Norge og kjent under navnet mulla Krekar. I sin bok «Med egne ord $»^{26}$ skildrer Krekar sin politiske og religiøse oppvåkning i Suleimaniyah: "Kommunismens ideer om klassekamp og samfunnsstruktur tiltrakk meg, men jeg hørte ikke hjemme i kommunismens ateisme eller dens etikk og moral ...Den islamske bevegelsen, derimot, representerte en helt annen dimensjon. Jeg besøkte moskeenes ro, og jeg begynte å be." ${ }^{27}$

Ved de kurdiske universitetene i Suleimaniyah og Irbil studerte Krekar arabisk, og leste dessuten islamsk litteratur på fritida. Her traff han også sin framtidige kone Rohkosh, som da var med i en kommunistisk ungdomsorganisasjon. Hun fant det likevel ikke vanskelig å gå over til Krekars radikale islamisme..$^{28}$

Det er verdt å merke seg at både islamisme og kommunisme framstår som mulige valg for studentene i Kurdistan. Også andre steder både i den muslimske verden og i Vesten har vi sett eksempler på at tidligere marxister har funnet seg til rette $\mathrm{i}$ islamistiske organisasjoner. ${ }^{29}$

Najmuddin Feraj Ahmeds bakgrunn er interessant fordi den svarer til et generelt mønster. Mange av de framtredende medlemmene av slike islamistgrupper har høyskoleutdannelse, gjerne innen tekniske fag, men mangler teologisk fagkunnskap. (Vogt 2004: 238 ff.) Mulla Krekar og andre åndelige ledere i slike grupper har derfor utviklet en forståelse av Koranen og hadithene basert på nærlesning av teksten uten å gå veien om innarbeidet tolkn- 


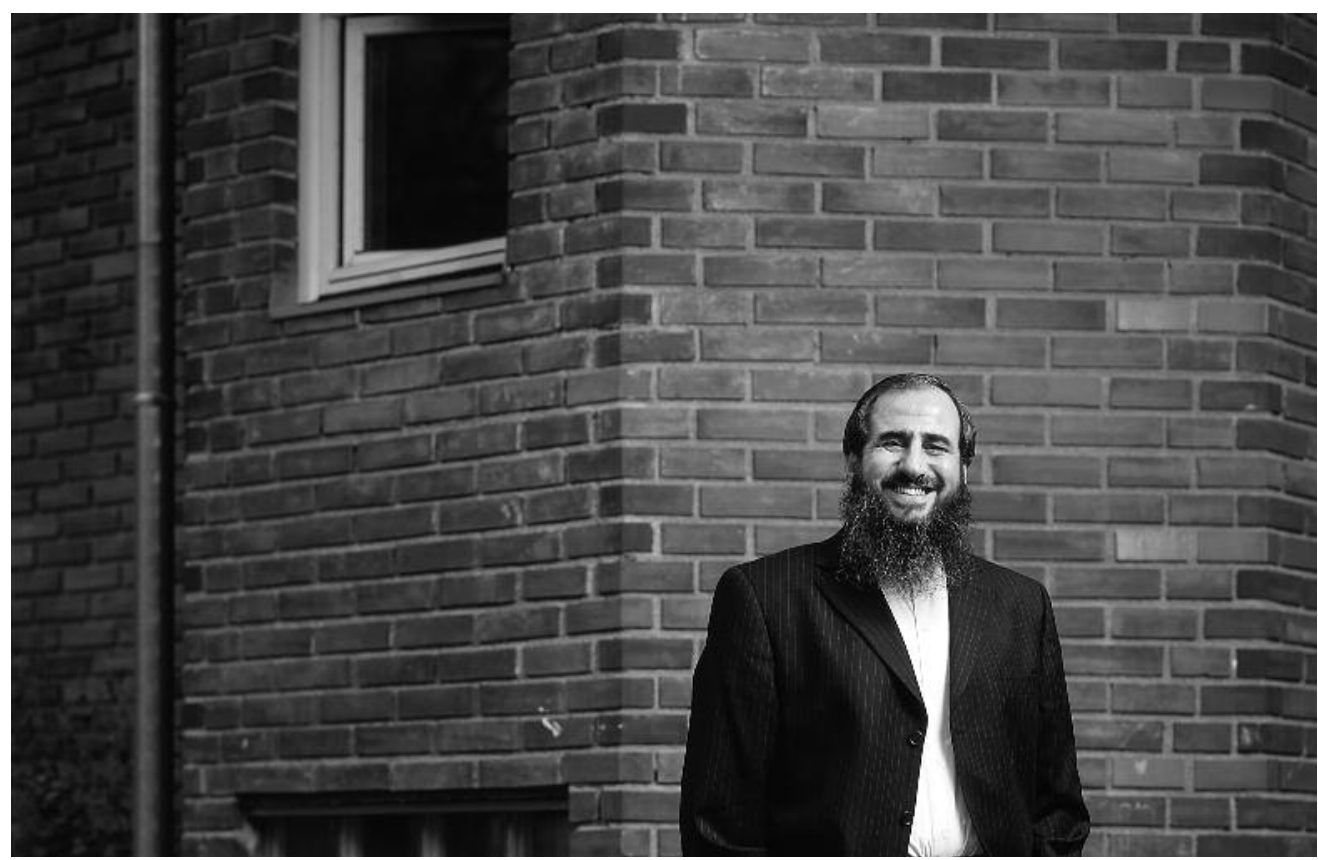

Mulla Krekar, eller Najmuddin Feraj Ahmed, som er hans egentlige navn, er grunnleggeren av den radikale islamistbevegelsen Ansar al-Islam.

FOTO: L-P LORENTZEN

ingstradisjon. Begrepet salafi, som betyr tilbake til røttene, innebærer nettopp en slik avvisning av den etablerte skriftforståelsen..$^{3^{\circ}}$ Krekar mener selv det ligger en innebygd konservatisme i sunni-islams maktstrukturer. I sin selvbiografi skriver han: "[..] det sunnimuslimske presteskapet [..] ser på makthaverne som en samlende faktor som det ikke må gjøres opprør mot." ${ }^{31}$

\section{Ansar ved makta}

I I982 hadde Krekar flyktet til Iran, og derfra forsøkt å danne en kurdisk islamsk milits med iransk støtte. Forsøket mislyktes til tross for at "grasrota levde i håpet om en gang å se en væpnet islamsk gruppe giøre sin entre i kurdisk politikk". Fra 1984 underviste han ved det islamske universitetet i Peshawar, der han sto i nær kontakt med de afghanske motstandsgruppene, og opprettet et herberge for kurdiske muja- hedin..$^{32}$

I I99I vendte Ahmed/Krekar tilbake til Kurdistan, der IMK nå var blitt en maktfaktor i det autonome kurdiske området. Mange andre kurdiske veteraner fra Afghanistan vendte også tilbake, sluttet seg sammen i ulike kampgrupper og rekrutterte lokale ungdommer. Disse gruppene var en vesentlig del av dem som etter 1996 brøt ut fra IMK, og som fra 1997 av ble makthavere i sitt eget islamistiske minikurdistan. ${ }^{33}$

De sharialovene Ansar legger til grunn for sin straffelov er basert på den strenge Hanbaliskolen innen islamsk lov, mens kurdiske sunnimuslimer tradisjonelt har fulgt lovskolen til Shafi' i. Dette har skilt kurdere fra andre sunnimuslimer, som stort sett følger lovskolen Hanafi. ${ }^{34}$ Det styresettet Ansar al-Islam innførte i sin enklave var derfor helt ulikt de religiøse så vel som de politiske tradisjonene i 

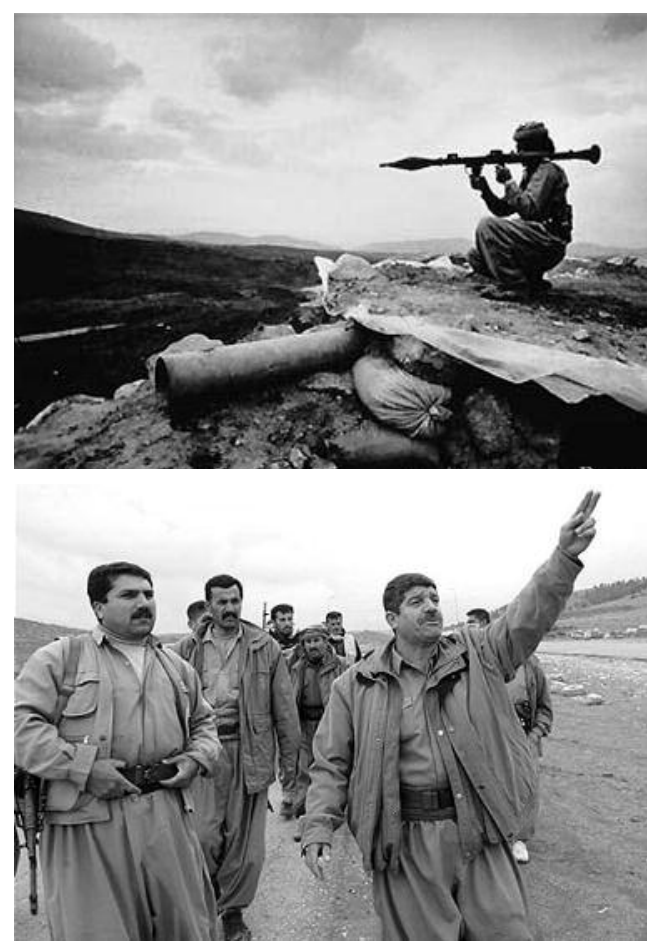

Kurdiske peshmergaer på oppdrag i fjellene.

område... En del av bakgrunnen for at en slik endring ble mulig ligger i svekkelsen av tradisjonell lovforståelse gjennom sekularisering og dyptgripende sosiale endringer.

Hawramath-området, der Ansars enklave ble opprettet, var tradisjonelt preget av sterk religiøs pluralisme, og en rekke religiøse minoriteter hadde funnet tilhold her. Som følge av krig og sosial uro var den opprinnelige befolkningen i landsbyene sterkt redusert. Den befolkningen Ansar al-Islam hersket over, var derfor et utvalg aktivister fra nær og fjern, og rester av en mer eller mindre velvillig sivilbefolkning. ${ }^{35}$

Området rommer flere landsbyer der en stor del av innbyggerne tilhørte al-Haqqa, og andre landsbyer med sarkofager, gravmæder for uortodokse sufisjeiker. Slike sarkofager er ofte pilgrimsmål for den

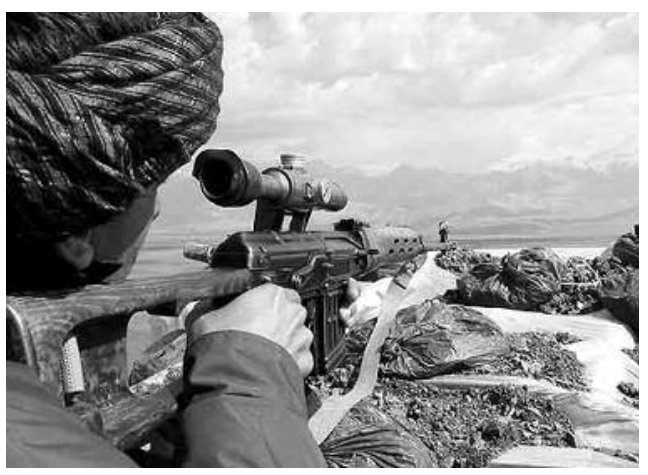

gravlagte sjeikens etterfølgere. Under Ansar fikk Haqqa-kurderne valget mellom å flykte eller gå over til sunni-islam. Muslimer som fulgte andre retninger enn Ansar al-Islams salafilære ble også forfulgt. Flere av de gamle sufigravmædene ble ødelagt, og levningene av de hellige menn kastet ut over bakken. ${ }^{36}$

Den uavhengige gruppa Human Rights Watch arbeider systematisk med å avdekke overgrep i Midtøsten. Ifølge HRW var det i enklaven påbudt å gå i moskeen og å bære skjegg (for menn) eller heldekkende slør (for kvinner). All utdanning for kvinner ble forbudt, og alle bilder av kvinner fjernet fra produkter i butikkene. Musikk i alle former ble forbudt, instrumenter, videospillere og parabolantenner ødelagt. Politiske motstandere, inkludert soldater fra PUKs vapnede styrker, ble torturert og grovt lemlestet. ${ }^{37}$ Til den norske journalisten Henrik Hovland fortalte landsbyboere at Ansar hadde pålagt småjenter å dekke seg til, forbudt sang og dans i brylluper og ilagt bøter for latter. ${ }^{38}$

\section{Ansar al-Islam og al-Qaida}

Ansars milits omfattet ikke bare lokale kurdere, men også en stor andel veteraner fra krigen i Afghanistan. Krekar avviser at afghanske eller tyrkiske mujahedin deltok, 
men innrømmer dermed at kurdiske og arabiske afghanistanveteraner var tilstede. ${ }^{39}$ I oppløpet til det amerikanske angrepet på Irak i 2003, forsøkte CIA å påvise en forbindelse mellom Ansar al-islam, Taliban og al-Qaida. En ideologisk forbindelse til Taliban er åpenbar; noen organisatorisk forbindelse har det derimot ikke vær mulig å påvise. I sin selvbiografi avviser Krekar enhver forbindelse til Al-Qaida, men han har i intervjuer med Der Spiegel og med det norske tidsskriftet Babylon rost Osama bin Laden og framhevet Talibanregimet

\section{mom \\ Akarakterisere Ansar som en avdeling av al-Qaida blir å tillegge al-Qaida et urealistisk organisasjonsmønster.}

som et godt forbilde for et muslimsk styresett. $^{40}$

Å karakterisere Ansar som "en avdeling av al-Qaida" blir likevel å tillegge al-Qaida et urealistisk organisasjonsmønster. Ansar har neppe tatt ordre fra noen, men har operert - og opererer fortsatt - innenfor en forståelse av virkeligheten som deles av Osama bin Laden og mange andre islamister. $^{4 \mathrm{~T}}$

Et viktig ledd i Ansar al-Islams kampanje mot de verdslige makthaverne i Sør-Kurdistan var opplæring av selvmordsbombere. En av disse var en I9 år gammel gutt, Didar Mohammed, som ble avslørt og arrestert da han var på vei inn $\mathrm{i}$ et av PUKs kontorer sommeren 2002. Til den britiske journalisten Jason Burke sa Didar: "Jeg mente det var min plikt å drepe funksjonærene [på PUK-kontoret] fordi de var vantro. Jeg gjorde min plikt i den hellige kampen for en sann islamsk stat i Kurdistan. Til siste øyeblikk var jeg glad for å dø." ${ }^{2}$

Som en del av det amerikanskledede angrepet på Irak våren 2003 ble Ansars enklave erobret av PUKs styrker med amerikansk støtte. Ansars tidligere støttespillere i Iran holdt seg i ro, men tillot Ansars peshmergaer å flykte over grensa. Et utilsiktet resultat av dette later til å være at endel av Ansar-aktivistene nå har utviklet et terrornettverk av den typen amerikanerne forsøkte å bevise at de tilhørte. En rekke seinere selvmordsaksjoner i det kurdiske området og andre deler av Irak har forbindelseslinjer til Ansar.

I Krekars selvbiografi nevnes det $i$ en bildetekst at hundre mennesker ble drept av selvmords-bombere i Irbil i februar 2004. Krekar unnlater å nevne at en tidligere ukjent gruppe med navnet Ansar al-Sunna tok på seg ansvaret for disse aksjonene og hevdet de ble utført til støtte for "våre brødre i Ansar al-Islam". . ${ }^{33}$ Underskriveren av oppropet og den antatte leder for Ansar al Sunna er Abdullah Shafee, som forøvrig har figurert sammen med mulla Krekar på et fotografi i Dagbladet. ${ }^{44}$

\section{Oppsummering}

De islamistiske grupperingene i Nord-Irak oppsto i en situasjon med voldsomme og raske sosiale endringer. Det sekulære Baathregimet i Bagdad ble konfrontert av sekulære kurdiske grupper, som i stor grad var basert på tradisjonelle klaninteresser og klient/patron-forbindelser. Islamistene framsto som en opposisjon innen opposisjonen, med front så vel mot Saddam Husseins brutale diktatur som mot de korrupte og - etter islamistenes syn degenererte klanlederne i de dominerende 
kurdiske partiene KDP og PUK.

IMK og de mange mindre islamistiske gruppene viser både moderne og premoderne trekk. IMK var opprinnelig nær knyttet til muslimbrødrene og den saudiarabiske wahhabisekten, men ble hurtig dominert av mer radikale tendenser, ikke minst gjennom kontakt med mujahedin som vendte tilbake fra krigen i Afghanistan. IMK framsto som moderne ved å appellere på tvers av klangrenser og ta avstand fra klanledernes og de etablerte partienes korrupsjon. Derfor appellerte bevegelsen også til studenter og annen ungdom.

Utbrytergruppene som fant sammen i Ansar al-islam hadde i større grad preg av å være en muslimsk reaksjon på sekularisme og modernisme. Den plasserer seg som en del av den globale retningen jihad salafi. Krekar og hans tilhengere pekte på Taliban som et mønstersamfunn, og tvang befolkningen i de landsbyene de okkuperte til å leve etter Ansars oppfatning av et tradisjonelt muslimsk liv. At disse "tradisjonene" var i klar strid med etablert livsstil i de berørte landsbyene ble verst for landsbyboerne.

Krigen i 2003 satte sluttstrek både for Baathregimet i Bagdad og for Ansars ministat i Hawramath, men har satt i gang en ny prosess der Ansar al-Islams aktivister er blitt del av en væpnet kamp mot så vel den amerikanske okkupasjonen som de verdslige makthaverne i det autonome kurdiske området.

Islamistenes framtidige innflytelse i irakisk Kurdistan er det altfor tidlig å uttale seg om.

\section{- $f$ •}

I Yildiz, Kerim: «The Kurds in Iraq. The Past, Present and I46
Future». Pluto Press, London 2004: 9.

2 Se for eksempel Ghareeb, Edmund: «The Kurdish Question in Iraq. Syracuse Univcersity Press, Syracuse I98I: 3 ff.

3 Shourush, Sami: "The Religious Composition of Kurdish Society", s. II4-I39 i Faleh, ed. «Ayatollahs, Sufis and Ideologues. Saqi Books, London 2002b: II5 ff.

4 Ibid: I27 ff.; Kreyenbroek, Philip G. «Religion and Religions in Kurdistan». s. 85-III i Kreyenbroek \& Allison (red.) Kurdish Culture and Identity. Zed Books, London I996.

5 Ibid: 94, 104/105.

6 Hakim, Helkot: "Kurds, Islam and State Nationalism", s.45-58 i Faleh, ed. «Ayatollahs, Sufis and Ideologues». Saqi Books, London 2002: 50.

7 Ibid: $47 \mathrm{ff}$

8 Yildiz 2004: 78-79.

9 Hakim 2002: 50.

Io Shourush, Sami, "Islamist Fundamentalist Movements among the Kurds". s. I77-I82 i Faleh, ed. «Ayatollahs, Sufis and Ideologues». Saqi Books, London 2002a: I78, se også Krekar, Mulla: «Med egne ord». Aschehoug, Oslo 2004 .

II Ibid: I79.

I2 Hakim 2002: 49

I3 Yildiz 2004: 27-28.

I4 Ibid: 34 .

I5 Ibid: $45 \mathrm{ff}$.

I6 Kreyenbroek, Philip G. «Religion and Religions in Kurdistan». s. 85-III i Kreyenbroek \& Allison (eds.) Kurdish Culture and Identity. Zed Books, London I996.

I7 Ibid: 96

I8 Burke, Jason: «Al-Quaeda - casting a shadow of terror». I.B. Tauris, London 2003: 201.

I9 Shourush 2002a: 179-80.

20 Burke 2003: 48

2I Ibid: $20 \mathrm{I}-2$.

22 Shourush 2002a: 179-80.

23 Burke 2003: 202.

24 Kepal, Gilles: «Jihad - the Trail of Political Islam». The Belknap Press, Cambridge, Massachusetts 2002: 220.

25 Bruke 2003: 202.

26 Krekar 2004.

27 Ibid: 22 
28 Ibid: $27 \mathrm{ff}$.

29 Se for eksempel Vogt, Kari: «Islams hus. Cappelen, Oslo 2004 [I995]: $54 \mathrm{ff}$.

30 Kepal 2002: 220.

3I Krekar 2004: 74 .

32 Ibid: $33 \mathrm{ff}$.

33 Bruke 2003: 201.

34 Kreyenbroek 1996.

35 Ibid.

36 Mirahmadi, Hedieh: "Jihadi tomb raiders". National Review Online, 2002. <http://www.nationalreview.com/ comment/comment-mirahmadir2I302.asp $>\quad$ (05-02 2004).

37 Human Rights Watch: "Ansar al-islam in Iraqi Kurdis$\mathrm{t}$ 2003.<http://hrw.org/backgrounder/mena/Ansar bko20503.htm > (25-OI 2004).

38 Hovland, Henrik: "Jakten på Krekars fortid” i Dagbladet, Oslo, 18. april 2004, s I9-23.

39 Krekar 2004: II5.

40 Olsen, Inger Anne: “Osama bin Laden er en god mann" i Aftenposten, Oslo, 7. januar $2004<\mathrm{http}: / /$ www.aften posten.no/nyheter/iriks/article703507.ece> (28-II- 2004); McNicol, Thomas og Jacob Høigilt: "Intervju med mulla Krekar" i Babylon, nr 2, 2003 s.78-85.

4I Burke 2003: I99 ff.

42 Burke, Jason: “How Kurdistan' s first suicide bomber changed his mind.” I The Observer, 25. august 2002. <http://observer.guardian.co.uk/worldview/story/o,II58I, 780I70,00.html>(08.10.2004).

43 Newscom: "Al-Qaida linked group claims blast." <http://www.smh.com.au/articles/2004/02/05/10758 $53963448 . h$ tml?oneclick=true $>$ (27-II 2004).

44 Hovland 2004. 